\title{
Prescription Pattern of Anti Microbial Agents in Patients of Appendicitis Admitted in Tertiary care Teaching Hospital: a Cross Sectional Study
}

\author{
Ghodki $S^{1}$, Borade $S^{2}$, Bhore $A^{3}$, Umale $N^{4}$, Bansod $K^{5}$, Bijwe $V^{6}$ \\ ${ }^{1}$ Dr. Sarang Ghodki, Senior Resident, Department of Pharmacology ${ }^{2}$ Dr Sanjio Borade , Senior Resident, Department of \\ Pharmacology, ${ }^{3}$ Dr Ashok Bhore, Professor and Head, Department of Pharmacology, ${ }^{4}$ Dr Narayan Umale, Professor and \\ Head, Department of Surgery ${ }^{5}$ Dr Kishor Bansod, Associate Professor, Department of Pharmacology, ${ }^{6}$ Dr. Varsha Bijwe, \\ Associate Professor, Department of Surgery. All are affiliated with Dr. Panjabrao Deshmukh Memorial Medical College, \\ Amravati, India.
}

Address for correspondence: Dr Sarang Ghodki, Email: sarang.ghodki@gmail.com

\begin{abstract}
Introduction: Appendicitis is one of the common conditions which usually require surgical intervention. It is almost always associated with inflammation with bacterial infection, treated either conservatively or surgically. In both situations, different types of antimicrobial agents (AMAs) are used. AMAs are used either in inadequate or over doses. This results in development of antimicrobial resistance in microorganisms and thereby increasing duration of stay, morbidity and cost of treatment. Objective: To Study the Prescription pattern of AMAs in patients of appendicitis admitted in Surgery ward of tertiary care teaching hospital. Method: It was a cross sectional study carried out over a period of six months. Data was collected from cases papers of surgery ward from medical record section. It was analyzed and evaluated on basis of various parameters like demographic distribution, complicated or uncomplicated cases, type of treatment, percentage of AMAs prescribed in order of preference, dose, duration, frequency and route of administration of AMAs (i.e. Rational use), average no. of AMAs per patient, incidence of surgical site infection, duration of stay in hospital, etc. Results: Out of 113 cases of appendicitis, only 33 (29.20\%) were treated rationally. Ceftriaxone and cefpodoxime were most frequently used AMAs. Average AMAs prescribed per patient were 3. Average of total duration of stay in hospital was 10 days. Conclusion: AMA prescription policy should be formulated and displayed in surgery ward for complicated and uncomplicated appendicitis cases to promote / facilitate rational prescription.
\end{abstract}

Key Words: Appendicitis, Rational Use, Antimicrobial agent, Antimicrobial Prescription

\section{Introduction}

Appendicitis is one of the common conditions which usually require surgical intervention. It was contended that the increase incidence was promoted primarily by an associated fall in dietary fiber intake or high protein diet $[1,2]$. Appendicitis is most common in teen-aged group, but seen at any age.

It is treated either conservatively or surgically [3]. In both situations, different types of antimicrobial agents (AMAs) are used, like Cefotaxim, Ceftriaxone, Piperacilline- Tazobactum, Cefazolin, cefixime, cefpodoxime, Ciprofloxacin, Amikacin etc.

Manuscript received: $21^{\text {st }}$ May 2014

Reviewed: $20^{\text {th }}$ June 2014

Author Corrected: $16^{\text {th }}$ Aug 2014

Accepted for Publication: $8^{\text {th }}$ Sep 2014
Appendicitis is almost always associated with inflammation secondary to bacterial infection. So, AMAs become the main stay in the management of appendicitis. It is observed everywhere that surgeons are not meticulous about administering AMAs properly. AMAs are used either in inadequate or over doses, is responsible for development of resistance and thereby increasing duration of stay, morbidity and cost of treatment.

Appendicitis is very frequently come across clinical condition in surgery department of our institute. There is no standard protocol for the management of appendicitis either conservatively or surgically with AMAs. It varies from surgeon to surgeon. Numbers of studies are available on, comparison between conservative management versus surgical intervention in appendicitis 
$[4,5]$. But, till date in our institute, work on prescription audit was not done. Hence we decided to study the prescription pattern of AMAs in cases of appendicitis admitted in surgery ward of Dr. Panjabrao Deshmukh Memorial Medical College, Amravati on the basis of choice of AMAs and their appropriate use in terms of dose, duration and frequency.

\section{Materials and Method}

Patients admitted to surgery ward of our institute were included in this study.

\section{Inclusion criteria:-}

1) Patients admitted in surgery ward diagnosed clinically and or sonographically as a case of appendicitis.

2) Age: 7 yrs and above.

\section{Exclusion criteria:-}

1) Patients of acute abdomen other than appendicitis.

\section{Study Design}

Type of study: Cross sectional study. Duration of study: 6 months

The Present Cross sectional study was carried out in the department of Pharmacology of Dr. Panjabrao Alias Bhausaheb Deshmukh Memorial Medical College and Hospital, Amravati. Data from case papers of diagnosed cases of appendicitis were collected from Medical record section. Data of patients admitted during $1^{\text {st }}$ December $2011-31^{\text {st }}$ May 2013 was collected. From that, 113 cases were selected on the basis of inclusion and exclusion criteria and were analyzed. An Ethical Committee approval was obtained from Institutional Ethical Committee.

\section{Method}

Prescription pattern of AMAs were studied on the basis of following points

1) Age and sex of the patient.

2) Cases: complicated or uncomplicated
3) Type of treatment: Alone AMAs or AMAs and Surgery.

4) Percentage of AMAs prescribed in the order of preference.

5) Dose, duration, frequency and Route of administration of AMAs.

6) No. of AMAs per patient.

7) Incidence of surgical site infection.

8) Duration of stay in hospital.

\section{Results}

Demographic data

Out of 113 patients of appendicitis admitted 69 (61.06\%) were male and 44 (38.94\%) were female. Male female ratio was $1.57: 1$.

Mean age (yrs.) of study population was 26.89. Mean duration of total stay in hospital (days) was 9.78. Mean duration of post operative stay in hospital (days) was 8.32. Mean interval of onset of symptoms and date of admission (in days) was 16.48. Mean time interval between admission and surgery (in days) was 1.97. Average AMAs prescribed to patients - 2.81.

In $84(74.34 \%)$ cases clinical diagnosis was acute appendicitis, while in $11(9.73 \%)$ and $8(7.08 \%)$ diagnosis was recurrent appendicitis and appendicular lump. respectively. Perforation was diagnosed in 6 (5.31\%).

In our study population, strategies of treatment were either conservative or operative. Operative procedures were done in $100(88.5 \%)$ cases, while rest $13(11.5 \%)$ were managed conservatively. Out of that 100,95 (84.07\%) were underwent emergency appendicectomy, while in $5(4.42 \%)$ interval appendicesctomy was done. In Surgical treatment choice of procedure was appendicectomy with laparotomy. Laproscopic appendicectomy was performed in only one case.

In our study, it was observed that $11(09.73 \%)$ cases were complicated (Perforation peritonitis with appendicular perforation) while rest were uncomplicated.

Table 1: Intra-operative Findings

\begin{tabular}{|l|l|l|l|}
\hline S.N. & Findings & No. of pts. $(\mathbf{n}=\mathbf{1 0 0})$ & $\mathbf{\%}$ \\
\hline 1 & Inflammed Appendics & 64 & 64 \\
\hline 2 & Not Mentioned & 19 & 19 \\
\hline 3 & Perforated Appendicitis & 11 & 11 \\
\hline 4 & Appendicular Lump & 06 & 06 \\
\hline & Total & 100 & 100 \\
\hline
\end{tabular}

*13 patients were excluded as they were managed conservatively. 
This table gives information of intra-operative findings. Maximum numbers of cases were of inflamed appendics 64 (64\%). In 19 (19\%) findings at surgical site was not mentioned.

In $11(11 \%)$ perforation were seen with localized or frank pus in right iliac fossa or peritoneum. Appendicular lump was seen in $06(06 \%)$ cases only.

While we focused on interval between admission and surgery, it was found that $4(3.54 \%)$ cases were operated on same day of admission, followed by 49 (43.36\%) on the next day of admission. Patients operated after 2 days were 14 (12.39\%). Number of patients operated 3and 4 days after admission were $10(8.85 \%)$ each.

Table 2: Trend of AMA administration in switch over

\begin{tabular}{|l|l|l|}
\hline Category & No. of pts. & $\mathbf{\%}$ \\
\hline IV and Oral AMA of same group & 65 & 57.52 \\
\hline IV and Oral AMA of different group & 34 & 30.09 \\
\hline Oral AMA not given & 6 & 05.31 \\
\hline IV AMA not given & 2 & 01.77 \\
\hline Other* & 6 & 05.31 \\
\hline
\end{tabular}

* One oral AMA belongs to group of that IV AMA but $2^{\text {nd }}$ one is of different group.

In our study, 65 (57.52\%) patients were prescribed IV and oral AMAs of same group. In 34(30.09\%) IV and oral AMAs were of different group. While in $6(5.31 \%)$ cases, out of 2 oral AMAs one belongs to group of IV AMA but not other one. In $6(5.31 \%)$ cases oral AMAs were not prescribed, while $2(1.77 \%)$ cases were managed on oral AMAs only.

Fig.1: Number of AMAs per patient

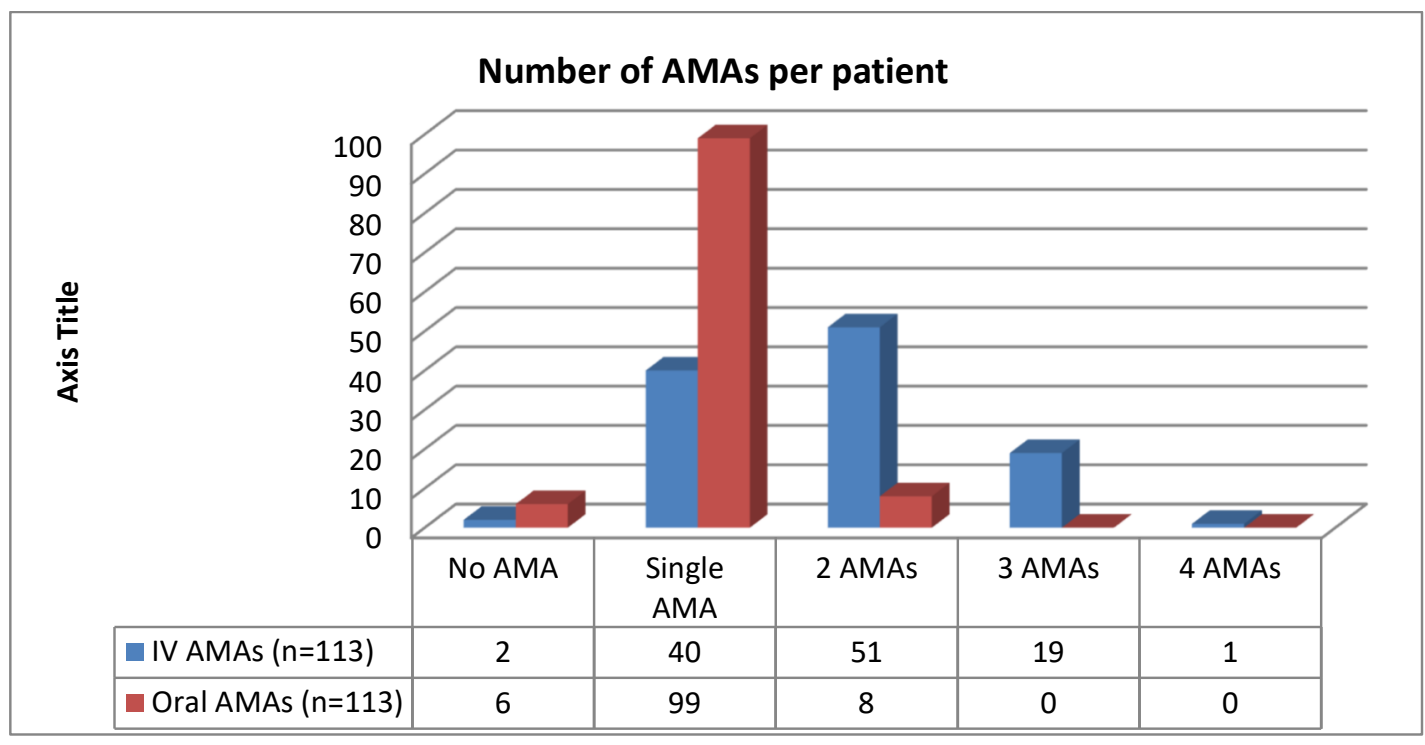

\section{Details of IV AMAs}

In our study single IV AMA was prescribed to 40 (35.39\%), followed by 2 AMAs in 51 (45.13), 3 AMAs in 19 (16.81\%). Only $1(0.89 \%)$ patient received 4 AMAs. While in $2(1.77 \%)$ cases IV AMAs were not prescribed. ( Fig.1)

\section{Details of Oral AMAs}

On the other hand, out of $113,99(87.61 \%)$ patients received single oral AMA. While 2 AMAs were prescribed in $8(7.08 \%)$. $6(5.31 \%)$ patients were not received any oral AMAs. 
Research Article

Table 3: Common AMAs with their minimum and maximum duration of administered to study population

\begin{tabular}{|l|l|l|l|l|l|}
\hline SN & AMAs & No. of patients & $\%$ & $\begin{array}{l}\text { Min. duration } \\
\text { (in days) }\end{array}$ & $\begin{array}{l}\text { Max. duration } \\
\text { (in days) }\end{array}$ \\
\hline 1 & Ceftriaxone IV & 62 & 54.87 & 1 & 10 \\
\hline 2 & Cefotaxime IV & 55 & 48.67 & 1 & 8 \\
\hline 3 & Amikacin IV & 53 & 46.90 & 1 & 12 \\
\hline 4 & Cefpodoxime Oral & 37 & 32.74 & 1 & 8 \\
\hline 5 & Cefixim Oral & 35 & 30.97 & 1 & 8 \\
\hline 6 & Amoxiclav Oral & 27 & 23.89 & 1 & 6 \\
\hline 7 & Cefoperazone IV & 12 & 10.62 & 1 & 9 \\
\hline 8 & O2 Oral & 10 & 8.85 & 1 & 7 \\
\hline 9 & Ciproflox IV & 07 & 6.19 & 1 & 7 \\
\hline
\end{tabular}

As per table $3^{\text {rd }}$ generation cephalosporin are most frequently prescribed antibiotics both in IV as well as oral formulation. IV Amikacin \& Amoxyclav are other frequently prescribed antibiotics.

Table 4: Appropriate and inappropriate use of AMAs on the basis of doses and frequency

\begin{tabular}{|c|c|c|c|c|c|c|}
\hline \multirow[t]{2}{*}{ SN } & \multirow[t]{2}{*}{ AMA } & \multirow{2}{*}{$\begin{array}{l}\text { No. of times } \\
\text { drug } \\
\text { prescribed }\end{array}$} & \multicolumn{2}{|l|}{ Doses } & \multicolumn{2}{|l|}{ Freq. } \\
\hline & & & $\begin{array}{l}\text { No. of times } \\
\text { Appropriate } \\
\text { Doses given }\end{array}$ & $\begin{array}{l}\text { No. of time } \\
\text { Inappropriate } \\
\text { Doses given }\end{array}$ & $\begin{array}{l}\text { No. of times } \\
\text { freq. was } \\
\text { Appropriate }\end{array}$ & $\begin{array}{l}\text { No. of times } \\
\text { freq. was } \\
\text { Inappropriate }\end{array}$ \\
\hline 1 & Ceftriaxone IV & 63 & 63 & 0 & 63 & 0 \\
\hline 2 & Cefotaxime IV & 58 & 1 & 57 & 8 & 50 \\
\hline 3 & Amikacin IV & 54 & 50 & 4 & 53 & 1 \\
\hline 4 & Cefoperazone IV & 12 & 12 & 0 & 12 & 0 \\
\hline 5 & Ciproflox IV & 7 & 7 & 0 & 7 & 0 \\
\hline 6 & Genta IV & 4 & 4 & 0 & 4 & 0 \\
\hline 7 & O 2 IV & 4 & 4 & 0 & 4 & 0 \\
\hline 8 & $\begin{array}{l}\text { Piperacillin } \\
\text { Tazobatam IV }\end{array}$ & 3 & 2 & 1 & 0 & 3 \\
\hline
\end{tabular}

As per table it is clear that ceftriaxone was given in appropriate doses $\&$ frequency most of times. IV cefotaxime was not given as per proper dosing \& frequency most of the time.

Table 5: Details of laboratory data and USG finding

\begin{tabular}{|l|l|l|l|l|l|l|l|l|l|l|}
\hline $\begin{array}{l}\text { Haematologic } \\
\text { Data }(\mathrm{n}=113)\end{array}$ & \multicolumn{2}{l|}{ USG $(\mathrm{n}=113)$} & \multicolumn{3}{l|}{ Haematologic Data and USG (n=113) } \\
\hline+ ve & $-\mathrm{ve}$ & $+\mathrm{ve}$ & $-\mathrm{ve}$ & $\begin{array}{l}\text { Not } \\
\text { Done }\end{array}$ & $\begin{array}{l}\text { Both } \\
+\mathrm{ve}\end{array}$ & $\begin{array}{l}\text { Both } \\
-\mathrm{ve}\end{array}$ & $\begin{array}{l}\text { USG +ve } \\
\text { Lab. -ve }\end{array}$ & $\begin{array}{l}\text { USG - ve } \\
\text { Lab. + ve }\end{array}$ & $\begin{array}{l}\text { Only Lab. } \\
+ \text { ve (USG } \\
\text { not done) }\end{array}$ & $\begin{array}{l}\text { Only Lab. } \\
- \text { ve. } \\
\text { (USG not } \\
\text { done) }\end{array}$ \\
\hline 38 & 75 & 55 & 14 & 44 & 26 & 10 & 30 & 03 & 09 & 35 \\
\hline $\begin{array}{l}63.63 \\
\%\end{array}$ & $\begin{array}{l}66.37 \\
\%\end{array}$ & $\begin{array}{l}48.67 \\
\%\end{array}$ & $\begin{array}{l}12.39 \\
\%\end{array}$ & $\begin{array}{l}38.94 \\
\%\end{array}$ & $23 \%$ & $\begin{array}{l}8.85 \\
\%\end{array}$ & $26.55 \%$ & $2.66 \%$ & $7.96 \%$ & $30.97 \%$ \\
\hline
\end{tabular}


Out of 113 , both haematological data and USG were supportive in $26(23 \%)$, while both were negative in $10(8.85 \%)$ cases. In $30(26.55 \%)$ patients USG report was positive but laboratory report was negative. On the other hand, laboratory data was positive but USG was negative in only $3(2.66 \%)$ cases.

We observed that in 44 patients USG was not done. Out of these 44 patients, laboratory data was positive in 9 (7.96\%), while negative in $35(30.97 \%)$.

Out of 113 cases of appendicitis, only $33(29.20 \%)$ were treated appropriately as far as dose and frequency was concerned i.e. Rationally $[6,7]$. Rest $80(70.80 \%)$ were treated irrationally.

\section{Discussion}

After reading number of research article it was found that almost all authors frame their studies on the basis of conservative Vs surgical management of appendicitis. Research article regarding prescription pattern of antibiotics in the patients of appendicitis was not found.

So the current project is undertaken to study the prescription pattern of AMAs patients of appendicitis admitted in tertiary care teaching hospital. Prescription pattern was evaluated on the basis of dose, duration and frequency of administration of AMAs.

Ideally the treatment of appendicitis must be start with intravenous fluids and broad-spectrum antibiotics to provide broad-spectrum coverage against enteric organisms. After appendectomy, patients with acute appendicitis are usually discharged within 24 hours.

Current evidence suggests that an additional dose of antibiotics after appendectomy in uncomplicated appendicitis is not necessary or recommended as it comes under clean surgery. [8]

The patients with perforated appendicitis will require antibiotic therapy postoperatively until clinical resolution has occurred. The antibiotic regimen employed in this situation has traditionally been triple-antibiotic therapy (like ampicillin, gentamicin, and clindamycin) Monotherapy with piperacillin/tazobactam for intraabdominal infections. [8]

In our study out of 113,11 cases were of perforated appendicitis treated with multidrug therapy. Remaining all were uncomplicated cases, but only 40 patients were treated with monotherapy. In similar study by Kumar BA et al all uncomplicated cases were treated with monotherapy. [8]

The aim of any medicine management system is to deliver the right medicine to the patient who needs the medicine. The steps of selection, procurement, and distribution are necessary precursors to the rational use of medicines.
The Conference of Experts on the Rational Use of Drugs, convened by the World HealthOrganization (WHO) in Nairobi in 1985, defined rational use as follows:

"The rational use of drugs requires that patients receive medications appropriate to their clinical needs, in doses that meet their own individual requirements, for an adequate period of time, and at the lowest cost to them and their community."

In our study it was observed that AMAs were used either excessively or timidly in surgical department. During the administration of AMAs precautions like adequate dose, frequency and duration are not taken into consideration. All these increase the incidence of drug resistance and total cost of treatment. [6,7]

There are no clear cut guidelines or recommendations for the optimal use of AMAs in appendicitis [9]. It is well understood that, whenever patient was switch over from IV AMA to oral, ideally it should be of same group to avoid unnecessary exposure of AMAs to microorganisms.

AMAs prescribed orally on discharge to the patient, the duration of course of oral AMA was not mentioned clearly.

In one research report, estimation of CRP value is found to be relevant in diagnosis and its consecutive titers have got prognostic significance. In our study CRP was not done in any patient. [10]

After reviewing literature, we have decided to group these patients as under

1) Prophylactic (Uncomplicated appendicitis - AMAs administered till 24-48 hr after surgery) [11]

2) Therapeutic (Complicated perforation with peritonitis) (12)

And we define further -

Available online at: www.ijmrr.in 521 | P a g e 
3) Empirical / Inappropriate [13,14] (if treatment is continued beyond duration of prophylaxis without any clinical and or laboratory evidence.)

4) Based on Microbiological (Pus culture and sensitivity report $[15,16]$

According to above, out of 100 cases, 11 (11\%) were treated therapeutically, while rest $89(89 \%)$ were treated empirically / inappropriately. None of the patient was treated prophylacticaly or on the basis of microbiological pus culture sensitivity reports.

There is clearly defined protocol for these in many institutes. In our institute no such classified indications or specific antibiotic policy is existing.

In most of research articles Post op stay in hospital is taken into consideration as clinical entity and immediate facilities of haematologic, microbiologic and radiologic investigations are available within short time to intervene earliest and hence length of post op stay carries significance. In our setup all these required bit longer period and hence total duration of stay in hospital carries significance in our study.

Irrational use of AMAs may lead to development of drug resistance. Close and meticulous observation of scar status may definitely cut down the use of AMAs.

\section{Conclusion}

Residents are first to attend the patient in emergency and they are the one who start the treatment for the $1^{\text {st }}$ time.

If they are properly trained and informed regarding rational use of AMAs it will improve the outcome in all respect. A standard AMA stewardship should be formulated, displayed and executed in surgical wards and casualty department to bring rationality in treatment.

\section{Funding: Nil}

\section{Conflict of interest: Nil}

\section{Permission from IRB: Yes}

\section{References}

1. Walker ARP, Segal I. "What causes appendicitis?" J clinical Gastroenterology 1990; 12:127-129.

2. F.Gregory Connell, Oshkosh. "Etiology of appendicitis." The American J of Surg 1937;37(2):232238.
3. Wojciechowicz KH, Hofkamp HJ, van Hulst RA. "Conservative treatment of acute appendicitis. An overview." International Maritime Health 2010;61 (4):189-272.

4. Hansson J, Ko“ rner U, Khorram-Manesh A, Solberg A, Lundholm K. "Randomized clinical trial of antibiotic therapy versus appendicectomy as primary treatment of acute appendicitis in unselected patients", British J of Surg 2009;96:473-481.

5. Ansaloni L, Catena F, Coccolini F, Ercolani G, Gazzotti F, Pasqualini E, Pinna AD, "Surgery versus conservative antibiotic treatment in acute appendicitis: a systematic review and meta-analysis of randomized controlled trials.” Digestive Surgery 2011;3:210-21.

6. Promoting rational use of medicines: core components, WHO Policy perspectives on Medicines, September 2002 World Health Organization Geneva. Page 1- 6.

7. Krishnakant Dave, Rational drug therapy, Bulletin of the society for rational therapy 1994; 5(1):02-05.

8. Bangari AK, Adiveni T, Manna PK, Mahesh VP, Junior Sundresh N. Studies on antibiotics prescribing pattern in surgical Wards of department of surgery at rajah muthiah Medical college hosipital. World Journal of Pharmacy and Pharmaceutical Sciences 2014;3 (7):832-871.

9. Inchien Chamisa. What Is the Role of Conservative Antibiotic Treatment in Early Appendicitis? Appendicitis - A Collection of Essays from Around the World 2012:95-106. www.intechopen.com assessed on $04-05-2014$.

10. Luckmann R. Incidence and case fatality rates for acute appendicitis in California: a population-based study of the effects of age. Am J Epidemiol 1989;129:905-209

11. Khan SA, Rao PGM, Rao A, Rodrigues G. Survey and evaluation of antibiotic prophylaxis usage in surgery wards of tertiary level institution before and after the implementation of clinical guidelines. Indian Journal of Surgery 2006;68(3):150 - 156.

12. Colizza S, Picconi A, Blasi G. Monitoring of antimicrobial prophylaxis in general surgery. $\mathrm{J}$. Chemother.

1999; 11:573.6. 
13. Bratzler DW, Dellinger EP, Olsen KM, Perl TM, Auwaerter PG, Bolon MK, et al., Clinical practice guidelines for antimicrobial prophylaxis in surgery, Am J Health-Syst Pharm 2013; 70:195-283.

14. Fernández HA, Monge V, Garcinuňo MA. Surgical antibiotic prophylaxis: effect in postoperative infections. Eur J Epidemiol 17:369, 2001.
15. Kasatpibal N, Nørgaard M, Sørensen HT, Schønheyder HC, Jamulitrat S, Chongsuvivatwong V. Risk of surgical site infection and efficacy of antibiotic prophylaxis: a cohort study of appendectomy patients in Thailand, BMC Infectious Diseases 2006, 6:111. http://www.biomedcentral.com/1471-2334/6/111.

16. Josiah Olusegun Alamu, Evaluation of antimicrobial use in a pediatric Intensive care unit, University of Iowa, Iowa Research Online 2009, http://ir.uiowa.edu

\section{How to cite this article?}

Ghodki S, Borade S, Bhore A, Umale N, Bansod K, Bijwe V. Prescription Pattern of Anti Microbial Agents in Patients of Appendicitis Admitted in Tertiary care Teaching Hospital: a Cross Sectional Study. Int J Med Res Rev 2014;2(6): $517-523$. doi:10.17511/ijmrr.2014.i06.02 